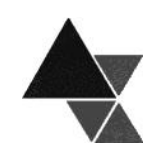

\title{
A rentabilidade da pecuária de corte no Brasil
}

\author{
Mariane Crespolini dos Santos ${ }^{1}$, Walter Belik ${ }^{2}$, Sergio De Zen ${ }^{3}$ e Luiz Henrique de Almeida
}

Este artigo teve como objetivo realizar uma análise da pecuária de corte no Brasil. Iniciamos apresentando a abordagem institucionalista para o entendimento do processo de desenvolvimento econômico e a sua relevância para a dinâmica. Na sequência é apresentada a evolução histórica da pecuária de corte no Brasil dando destaque para a questão das externalidades provocadas pela sua expansão e o mercado global de alimentos. Na parte empírica, trabalhamos com os dados de 193 propriedades modais de pecuária de corte obtidas em levantamento do Centro de Estudos Avançados em Economia Aplicada (Cepea/Esalq/USP), no período de 2002 a 2014, em 13 estados brasileiros, onde concentra-se $90 \%$ do rebanho nacional. Nesse levantamento foi possível verificar que, em mais de $40 \%$ das propriedades de pecuária de corte as receitas não são suficientes para cobrir os custos efetivos e as depreciações, e em mais de $90 \%$ as receitas não remuneram o custo de oportunidade do capital investido. As motivações dos pecuaristas para continuarem na atividade são elucidadas, mas, sem dúvida o aparato institucional brasileiro favorece as características do modelo produtivo predominante.

Palavras-chave: pecuária de corte, rentabilidade, uso da terra, desenvolvimento rural.

\section{The livestock profitability in Brazil}

This article will perform an analysis on the Brazilian livestock production. We begin presenting the institutional approach to understand the economic development process and its relevance for the dynamic. Subsequently the livestock production evolution in Brazil will be shown, highlighting the externalities provoked by its expansion and the global food market. In the empirical part, we worked with data from 193 modal livestock properties, obtained through field research, developed by the Center for Advanced Studies in Applied Economics (Cepea/Esalq/USP), in 13 Brazilian states. This states gathered possessed $90 \%$ of the national cattle flock in the period from 2002 to 2014. The research showed that more than $40 \%$ of the livestock properties had no sufficient revenue to cover the effective costs and depreciations, and in more than $90 \%$ of the properties revenues did not paid the opportunity cost of invested capital. The livestock producers' motivations are clarified, although, without a doubt, the Brazilian institutional apparatus favors the characteristics of the predominant production model.

Key-words: beef cattle production, profitability, land use, rural development.

\footnotetext{
${ }^{1}$ Mestranda em Desenvolvimento Econômico. Universidade Estadual de Campinas - UNICAMP. Correspondência: Av. 31 de Março no 1.001, Paulicéia - Piracicaba - SP. Telefones: (19) 3302-9247 e (19) 983144-690. CEP: 13424-305. E-mail:macrespolini@gmail.com

${ }_{2}^{2}$ Professor Titular do Instituto de Economia da Universidade Estadual de Campinas - UNICAMP. E-mail: belik@eco.unicamp.br

${ }^{3}$ Professor Doutor da Escola Superior de Agricultura “Luiz de Queiroz” - ESALQ. Universidade de São Paulo - USP. E-mail. sergdzen@usp.br

${ }^{4}$ Mestrando em Desenvolvimento Econômico. Universidade Estadual de Campinas - UNICAMP. E-mail. luizhenrique.dealmeida@gmail.com
} 


\section{INTRODUÇÃO}

A pecuária de corte no Brasil teve início praticamente no mesmo período da colonização. Primeiramente, a atividade forneceu animais para outras culturas e, em seguida, atendeu a demanda interna por proteína animal. A partir da década de 30, com as políticas de ocupação e desenvolvimento, o governo passou a estimular a ocupação do CentroOeste. Neste processo, inicialmente a pecuária de corte extensiva se apresentava como a única atividade econômica, posteriormente outras atividades também foram implantadas.

Após a ocupação do Centro-Oeste, já na década de 70, o Estado brasileiro enfatizou a importância do desenvolvimento da região da Amazônia e a expansão da pecuária caminhou para essa região. Ao exigir baixos níveis de capital, pouco preparo para o solo e poucas restrições associadas a relevo, após a retirada da madeira, a pecuária de corte exerceu um papel importante como atividade econômica pioneira.

A ocupação dessas regiões com a expansão da fronteira agrícola, que continua acontecendo, apresenta externalidades ambientais negativas e denota a baixa eficiência na utilização dos recursos naturais. Em relação ao desenvolvimento social, a pecuária tem um alto potencial de geração de empregos por área, mas o atual modelo de exploração - baseado na ocupação extensiva do território não favorece a geração de empregos. Ademais, a exploração da pecuária em áreas da floresta amazônica, reservas extrativistas e terras indígenas provoca conflitos e as disputas pela posse de terra continuam acontecendo.

Argumentamos neste artigo que o contexto histórico e os incentivos governamentais, lentamente, construíram instituições que acabam por legitimar esse modelo de pecuária de corte extensiva. Nesse sentido, a produtividade, assim como a rentabilidade desta atividade poderiam ser muito mais expressivas, se houvessem esforços para intensificá-la. Outras motivações permeiam as decisões de investir e produzir dos pecuaristas brasileiros e estão ligadas ao processo de valorização das terras ocupadas. Para demonstrar este argumento, trabalhamos comparativamente os dados de rentabilidade de 193 propriedades de pecuária de corte, em 13 estados brasileiros.

\section{REVISÃO BIBLIOGRÁFICA}

Existe uma discussão importante sobre o que permeia e diferencia o crescimento e o desenvolvimento econômico. $\mathrm{O}$ primeiro representa $\mathrm{O}$ crescimento do Produto Interno Bruto (PIB), que além de não refletir as reduções das desigualdades sociais, captura apenas os bens comercializados. Já o desenvolvimento econômico é um conceito muito mais abrangente, onde "a melhoria na qualidade de vida deve claramente ser o elemento essencial (...) de todo exercício econômico" [1].

Políticas públicas efetivas que possam alcançar o desenvolvimento econômico dependem de intervenções corretas e para tanto torna-se necessário desprender-se do paradigma neoclássico de que, no longo prazo, o equilíbrio e o desenvolvimento serão atingidos. No mundo real, há assimetrias de informação, os agentes não são substantivamente racionais e tampouco maximizadores de lucro [2]. Consequentemente, o mercado não é apenas um ponto de equilibrio entre preço e quantidade ou oferta e procura, mas sim o resultado de construções sociais, que refletem o ambiente institucional em que se inserem. É uma realidade muito mais complexa onde, as instituições cumprem o papel de reduzir a incerteza e incentivam o avanço das ações humanas coordenadas [3].

\footnotetext{
"As instituições são as restrições impostas pelos humanos nas suas interações. Consistem em regras formais (constituições, leis, estatutos, regulamentos e direitos comuns) e informais (convenções, normas, e códigos de conduta). As instituições definem, (...), as combinações de risco e recompensa que podem ser construídos com os recursos disponíveis em uma economia" [4].
}

A sociologia econômica agrega conceitos importantes à economia das instituições. A interação entre direitos de propriedade, estrutura de governança, regras de troca e concepção de controle estabelecem os contornos daquilo que denominamos o mercado. Um ponto fundamental destacado por essa corrente é que "Leis e práticas aceitas frequentemente refletem os interesses das forças mais organizadas da sociedade" [5]. 
Em sociedades com crescimento econômico, com concentração de ativos e de renda, é complicado formar estruturas de cooperação. A confiança é apoiada em vínculos hierárquicos localizados, bloqueando a ampliação do círculo de relações sociais. Desta forma, o desenvolvimento não reside em dons naturais, na acumulação de riqueza, ou tampouco nas capacidades humanas, mas sim nas instituições, nas ações coordenadas dos indivíduos e dos grupos sociais mais organizados [ ${ }^{6}$.

Nesse sentido, a agricultura e o desenvolvimento rural brasileiro só podem ser entendidos a partir da organização dos grupos sociais e das instituições construídas a partir da sua interação. Enquanto área de conhecimento, o rural tem sido analisado em oposição ao conceito de urbano e está amparado fundamentalmente na produção Contudo, a literatura recente já aponta um consenso entre os autores baseado em quatro pontos:

i) rural não é sinônimo de agrícola, assim como não tem exclusividade sobre este;

ii) Se o estabelecimento é multifuncional (produção agrícola, industrial, serviços ambientais, moradia social etc.), as atividades desenvolvidas pelos agentes tornamse pluriativas;

iii) as áreas rurais devem ser definidas a partir da sua densidade populacional que deve ser relativamente baixa;

iv) não há um isolamento absoluto entre espaços rurais e áreas urbanas, já que redes mercantis, sociais e institucionais se estabelecem entre estes espaços [7].

Haveria um quinto ponto a ser destacado que é a importância maior do rural nas políticas de Segurança Alimentar e Nutricional (SAN). Isso porque as maiores proporções da pobreza no Brasil ocorrem no meio rural e consequentemente, a falta de acesso ao alimento também ocorre nestas áreas. Além disso, o meio rural é determinante para a garantia da segurança alimentar de toda a população nas suas diferentes dimensões ${ }^{5}$.

5 Segundo o Suplemento Especial de Segurança Alimentar e Nutricional da PNAD Pesquisa Nacional por Amostragem de Domicilios do IBGE de 2013, uma proporção $40,1 \%$ da população residente no setor rural declarou estar em situação de insegurança alimentar (fraca, moderada ou grave) em comparação com $23,3 \%$ dos residentes no meio urbano.
Levando-se em consideração esses aspectos, podemos afirmar que os territórios rurais não são definidos pelos limites físicos, mas são resultados do modo de organização social e no uso dos sistemas naturais. Isto abre campo de cooperação entre ciências sociais e naturais no conhecimento desta relação [ $[$. Tanto que, a própria legislação destaca a função social da propriedade rural:

"A função social é cumprida quando a propriedade rural atende simultaneamente, segundo graus e critérios estabelecidos nesta lei, os seguintes requisitos: I aproveitamento racional e adequado; II - utilização adequada dos recursos naturais disponíveis e preservação do meio ambiente; III - observância das disposições que regulam as relações de trabalho; IV - exploração que favoreça o bem-estar dos proprietários e dos trabalhadores" (Artigo 186 da Constituição Brasileira) ${ }^{[8]}$.

Em alguns setores da agricultura brasileira, as propriedades rurais não cumprem devidamente a sua função social, como prevê a lei. Isto é um processo atual, mas que tem em suas raízes a própria formação econômica e institucional brasileira. A pecuária de corte tem apresentado diversos exemplos nesse sentido.

Com as primeiras ocupações portuguesas no Brasil, a pecuária de corte provia proteína animal para a população e também animais para tração nos cultivos agrícolas. De forma extensiva e rudimentar, a atividade tornou-se um importante fator de ocupação e integração do território [9].

Depois do desenvolvimento das regiões Sul, Sudeste e litorânea, a ocupação de novas áreas ocorreu principalmente rumo a pouco habitada região do Centro-Oeste brasileiro. No fim da década de 30, Vargas lançou o programa "Marcha para o Oeste", justamente para povoar aquele território [10]. Após algumas décadas, à medida que esse processo se acentuou e as áreas foram se esgotando, a necessidade de novas terras começou a pressionar a região da Amazônia. Alguns autores chamam este processo de "a colonização pela pata do boi" [11].

No início dos anos 70 o Governo Federal deu início aos programas de incentivo à colonização e à construção de rodovias na região, dentro dos chamados 
Planos Nacionais de Desenvolvimento (PND I, II e III). Com esses programas, aumentaram os investimentos de capitais estrangeiros, promovendo a consolidação de uma infraestrutura capaz de alavancar o desenvolvimento de áreas fronteiriças na floresta ${ }^{[12]}$.

Com objetivo de contribuir para a transformação de grandes áreas de mata em áreas cultiváveis e também confiantes nas promessas dos líderes políticos, brasileiros dos estados de São Paulo e Paraná, e mais tarde do Rio Grande do Sul, mudaramse para as regiões de fronteira. Em 2012, no levantamento realizado pelo Cepea (Centro de Estudos Avançados em Economia Aplicada da ESALQ - USP) no estado do Pará, $90 \%$ dos pecuaristas que participaram da reunião tinham estes estados como origem.

Como resultado do processo histórico e também influência política, os interesses da grande propriedade fundiária resistem a qualquer forma de restrição ao direito de propriedade da terra, seja opondo-se à legislação fundiária, seja sabotando sua efetiva aplicação.

O item II do $\int 2^{\circ}$ do Art. $6^{\circ}$ da Lei 8.629/1993 [13] estabelece que $\mathrm{O}$ aproveitamento racional $\mathrm{e}$ adequado para a propriedade onde ocorre a atividade pecuária deve atender um índice mínimo de lotação (em Unidade Animal - $450 \mathrm{~kg} /$ hectare) definido pelo Poder Executivo e específico para cada Microrregião Homogênea. Se o pecuarista alcança esse índice, todas as áreas de pastagens nativas e plantadas são consideradas efetivamente utilizadas (Item II, $\int 3^{\circ}$ do mesmo Artigo) [13]. Em outras palavras, obedecendo o índice de lotação específico, a propriedade é produtiva.
Caso a propriedade não cumpra os critérios de função social, a mesma está sujeita à desapropriação por interesse social para fins de reforma agrária, ou seja, um processo de caráter sancionatório (de acordo com Art. 184 da Constituição Federal de 1988) [8]. No entanto, o Art. 185 considera como exceções a esse tipo de desapropriação: I - a pequena e média propriedade rural, assim definida em lei, desde que seu proprietário não possua outra; e II - a propriedade produtiva ${ }^{[8]}$.

Desta forma, as leis que conformam o ambiente institucional regulatório da propriedade de terras no Brasil são ineficientes para coibir o seu uso especulativo na atividade pecuária. Principalmente em regiões de baixa densidade populacional, não há atividade econômica capaz de competir com a combinação de ocupação de terras devolutas, a extração da madeira, a instalação da pecuária de corte e a posterior valorização da terra ${ }^{[14]}$.

Mesmo que o crescimento do rebanho e da agroindústria suscite empregos, estes não são suficientes para promover o desenvolvimento rural em todas as suas esferas. Nos principais estados produtores, poucos estabelecimentos ocupam a maior parte da área agricultável. No Mato Grosso do Sul, por exemplo, $10 \%$ dos estabelecimentos são maiores que mil hectares e ocupam aproximadamente $80 \%$ da área agrícola total sob uso das propriedades no estado, Figura 1. 
Figura 1. Propriedades acima de 1.000 hectares ocupando a área agrícola total e pelo número de propriedades, por UF, em 2006.

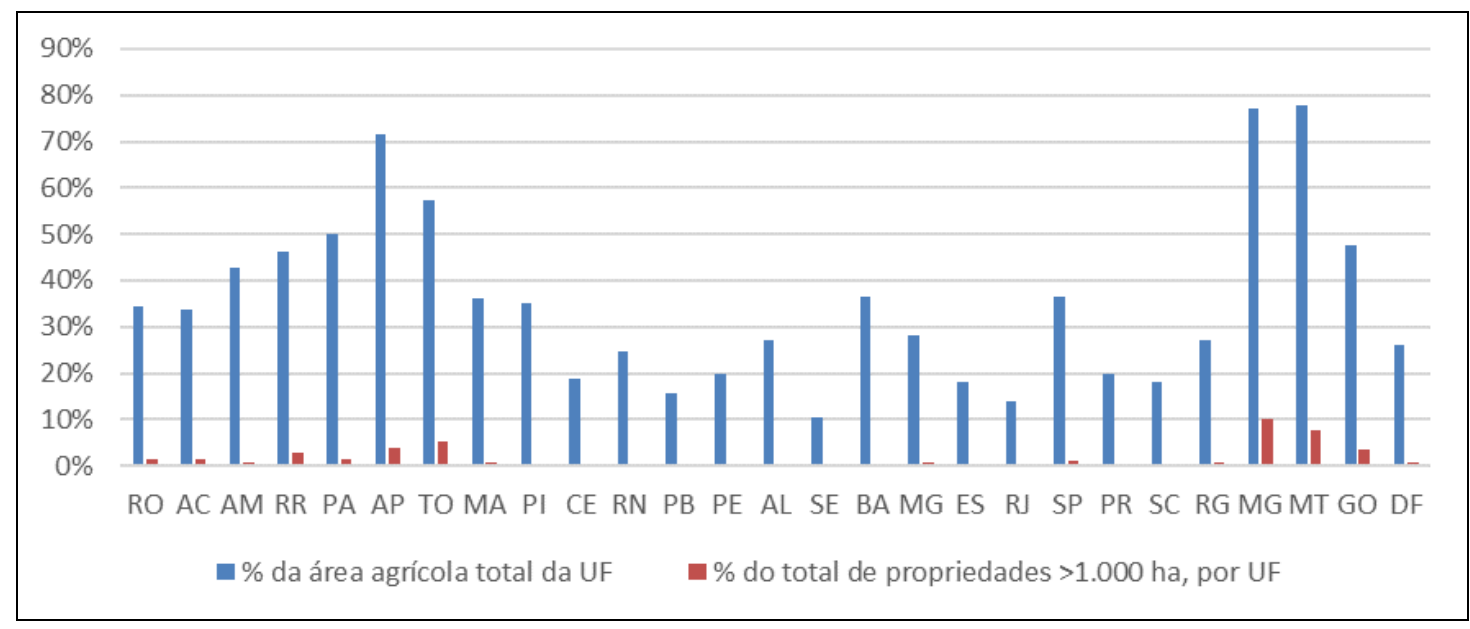

Fonte: Censo Agropecuário IBGE, 2006 [15].

Além dos problemas sociais, os impactos ambientais da atividade são expressivos, ainda mais nas regiões de fronteira agrícola ${ }^{6}$. A pecuária exige baixos níveis de capital, pouco preparo para o solo e apresenta poucas restrições associadas a relevo e a áreas livres de troncos em florestas recentemente desmatadas. Esses fatores fazem da pecuária a atividade mais intensamente associada aos processos de desmatamento na maior parte da região Amazônica [17].

Em 2013, a área total desmatada na Amazônia Legal foi 4,3 vezes inferior à de 2003, mesmo assim, entre 2012 e 2013 o valor voltou a subir. No último ano, a área desmatada no Pará estado onde a pecuária de corte é expressiva, representou $40,7 \%$ do total da área desmatada na Amazônia Legal, como demonstrado na Tabela 1.

\footnotetext{
${ }^{6}$ Neste artigo, a definição de fronteira é a estabelecida por Neiva [16]. A ocupação de áreas primitivas é realizada primeiramente pela fronteira demográfica, com pequenos produtores, colonos e artesãos. Em seguida, vem a frente econômica, representada por capitalistas e grandes produtores. A fronteira agrícola é econômica.
} 
Tabela 1. Taxa de desmatamento anual $\left(\mathrm{km}^{2} / \mathrm{ano}\right)$

\begin{tabular}{l|r|r|r|r|r|r|r|r|r|r|r}
\hline \multirow{2}{*}{ Estados } & \multicolumn{10}{c}{ Anos } \\
\cline { 2 - 12 } & 2003 & 2004 & 2005 & 2006 & 2007 & 2008 & 2009 & 2010 & 2011 & 2012 & $2013^{*}$ \\
\hline Acre & 1.078 & 728 & 592 & 398 & 184 & 254 & 167 & 259 & 280 & 305 & 199 \\
Amazonas & 1.558 & 1.232 & 775 & 788 & 610 & 604 & 405 & 595 & 502 & 523 & 562 \\
Amapá & 25 & 46 & 33 & 30 & 39 & 100 & 70 & 53 & 66 & 27 & 11 \\
Maranhão & 993 & 755 & 922 & 674 & 631 & 1.271 & 828 & 712 & 396 & 269 & 382 \\
Mato Grosso & 10.405 & 11.814 & 7.145 & 4.333 & 2.678 & 3.258 & 1.049 & 871 & 1.120 & 757 & 1.149 \\
Pará & 7.145 & 8.870 & 5.899 & 5.659 & 5.526 & 5.607 & 4.281 & 3.770 & 3.008 & 1.741 & 2.379 \\
Rondônia & 3.597 & 3.858 & 3.244 & 2.049 & 1.611 & 1.136 & 482 & 435 & 865 & 773 & 933 \\
Roraima & 439 & 311 & 133 & 231 & 309 & 574 & 121 & 256 & 141 & 124 & 185 \\
Tocantins & 156 & 158 & 271 & 124 & 63 & 107 & 61 & 49 & 40 & 52 & 43 \\
Amazônia Legal & 25.396 & 27.772 & 19.014 & 14.286 & 11.651 & 12.911 & 7.464 & 7.000 & 6.418 & 4.571 & 5.843 \\
\hline *Valor estiman & & & & & & & & & &
\end{tabular}

Fonte: Prodes/INPE, 2014 [18].

No bioma Amazônia, em áreas produtivas, ou seja, aquelas que não são Área de Proteção Permanente (APP) ou Reserva Legal (RL), onde há pecuária de corte estabelecida, o extrativismo madeireiro e não madeireiro, ecoturismo ou ainda estocagem de carbono não conseguem competir economicamente [19].

Além do desmatamento, a pecuária provoca outros impactos ambientais relevantes não só na Amazônia mas também em todas as regiões brasileiras. A redução da biodiversidade devido à destruição dos biomas naturais, a compactação e erosão do solo, consequentemente o assoreamento dos rios e também a expressiva emissão de Gases do Efeito Estufa.

Estes impactos poderiam ser mitigados se o manejo do rebanho bovino fosse realizado de forma mais intensiva. Por exemplo, Almeida [20] demonstrou que criando os animais em sistema extensivo, mas finalizando $\mathrm{em}$ confinamento, a redução da emissão de $\mathrm{CO} 2$ equivalente emitido seria de $17 \%$ menor por quilo de carne.

Complementarmente aos motivos de especulação, outros fatores também estimulam a atividade na abertura de novas áreas. Por exemplo, o avanço e consolidação de outras culturas agrícolas, como a cana de açúcar e a soja [21].
O Brasil ocupa posições de liderança no comércio mundial de produtos agrícolas e isso, sem dúvida, tem proporcionado consequências positivas para a balança comercial brasileira, assim como para a estabilidade econômica interna. No entanto, aumentos na produção e exportação não necessariamente se traduzem por desenvolvimento social e rural e também podem colocar em risco a segurança alimentar se não houver uma estratégia voltada para garantir alimentação a preços acessíveis para a população [22].

Com o processo de globalização, há um novo modelo de organização imposto ao setor rural, onde o mercado global e o sistema de linha de montagem orientam a formação dos "Impérios Alimentares" [23]. Desta forma, nem todas as mudanças institucionais tem impactos positivos para a sociedade [24].

A supremacia dos mercados globais pressiona o preço dos alimentos, as desigualdades de acesso aos mesmos, assim como os desperdícios, elucidando as contradições do regime alimentar mundial [25]. Essas contradições se espelham na demanda crescente pelas carnes processadas e a falta de orientação e regulação por parte das políticas públicas de forma a promover uma pecuária sustentável. 


\section{MATERIAIS E MÉTODOS}

O custo de produção de pecuária de corte é acompanhado pelo Cepea/Esalq/USP através do sistema de painel desde 2002. Até Junho de 2014 foram realizados 193 painéis de pecuária de corte, em 13 estados brasileiros. Nestes estados concentram-se $90 \%$ do rebanho nacional, de acordo com o IBGE [15]. A Figura 2 apresenta os painéis de pecuária de corte e também de pecuária de leite. $\mathrm{O}$ raio dos círculos representa o número de vezes em que a região foi visitada.

Figura 2. Painéis de pecuária de corte e de leite realizados pelo Cepea, 2002 a 2014.

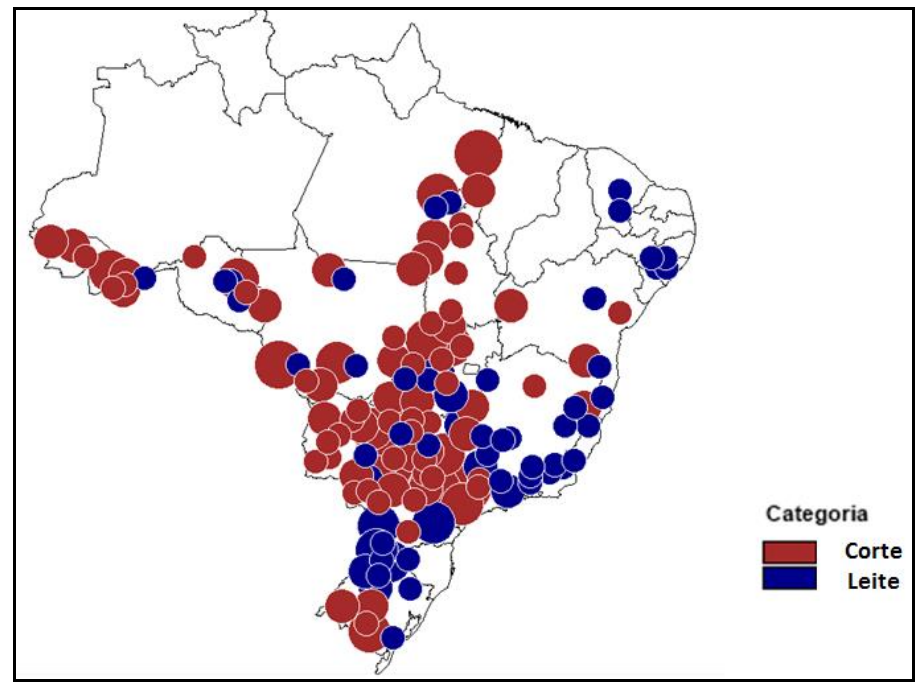

Fonte: Elaborado pelos autores, com base nos dados do Cepea [26].

Dada à dinâmica e mudança da atividade, os painéis são realizados anualmente e as regiões voltam a ser visitadas a cada dois ou três anos. O objetivo consiste em definir e caracterizar as propriedades típicas de cada região. Após este levantamento, a evolução dos preços dos insumos é acompanhada mensalmente com a finalidade de fazer $\mathrm{o}$ acompanhamento dos custos de produção dessas atividades.

\section{Sistema de Painel}

Enquanto metodologia de levantamento de dados primários, o painel é uma técnica de avaliação qualitativa comumente utilizada na investigação social. Este método revela mais informações do que as obtidas a partir de outros tipos de levantamentos, tais como as pesquisas individuais. Isto porque os participantes sentem-se livres para revelar a natureza e as origens de suas opiniões sobre um determinado assunto, permitindo que pesquisadores entendam as questões de uma forma mais ampla [27].

Uma das principais vantagens deste método é o seu custo baixo sem comprometimento da qualidade das informações. A metodologia de painéis vem sendo largamente utilizada nos Estados Unidos pelo seu Departamento de Agricultura. No Cepea, a metodologia vem sendo utilizada há dez anos, com resultados bastante satisfatórios.

A técnica de painel consiste em uma reunião com um grupo formado por pesquisadores, técnicos regionais e produtores para discussão e entendimento do sistema de produção agropecuário típico de uma dada região. Participam por volta de oito a 12 pessoas. As reuniões são agendadas com antecedência, utilizando-se de contatos em sindicatos regionais. 
Nos painéis, para que todos os participantes interajam, utiliza-se um computador portátil e um aparelho destinado a projetar a planilha de levantamento de dados das propriedades rurais previamente elaboradas. Esta planilha contém os seguintes tópicos:

- Descrição da propriedade: contém dados gerais sobre a área total da propriedade e da sua subdivisão em área de benfeitorias, pastagem cultivada e perene, área destinada à agricultura e áreas de mata nativa (reservas florestais, brejos, morros, entre outros). Nesta planilha, levanta-se também o valor do hectare e o valor pago pelo arrendamento da área para estimativa do capital investido e custo de oportunidade da atividade, respectivamente.

- Inventário: contém dados das construções e benfeitorias da propriedade típica, considerando o valor de uma nova construção, vida útil, valor residual e demais especificações. Além disso, da mesma forma são coletadas informações de máquinas, implementos, equipamentos e utilitários da propriedade. Para as máquinas são estimados os valores para cálculo do custo operacional a partir da manutenção e gasto de combustível. De forma semelhante os custos com combustivel também são estimados para os utilitários utilizados na atividade.

- Rebanho: compreende dados sobre a raça dos bovinos, quantidade de bezerros, vacas e touros - diferenciando-os em categorias. Também são levantados os indicadores de produção como taxa de mortalidade (pré e pós desmama), relação vaca/touro, idade do primeiro parto, intervalo entre partos, crias produzidas por vaca, taxa de natalidade (multíparas e matrizes), idade de abate do boi gordo ou venda do animal, taxa de lotação de pasto e total, produção de leite por animal, descarte de animais, ganho de peso e informações de comercialização (compra e venda) do rebanho.

- Pastagem: compreende a área de pastagem e a sua vida útil; nesta planilha são calculados os custos para a formação/reforma, começando pelo de operação, mão de obra e por fim dos insumos utilizados. Além disso, são levantados os dados do manejo da manutenção da(s) área(s) de pasto da propriedade.
- Agricultura: descreve os dados, caso na propriedade típica exista área também com agricultura. São levantadas informações sobre a formação e manejo da lavoura. $\mathrm{Na}$ atividade leiteira é mais comum a presença de agricultura que varia normalmente de áreas destinadas para milho silagem, cana-de-açúcar e culturas de inverno - destinadas normalmente à alimentação dos animais.

- Mão de obra: contém o levantamento do número de funcionários da fazenda $\mathrm{e}$ respectivos salários com suas respectivas taxas e recolhimentos; apresenta também o pró-labore do proprietário, além dos dias trabalhados ao ano pelos funcionários

- Suplementação: dados referentes à suplementação mineral do rebanho da propriedade típica, possui a discriminação dos produtos utilizados, preços, e a categoria do rebanho que consome os produtos e suas respectivas quantidades. Também é analisada a forma da distribuição da suplementação aos animais.

- Alimentação: caso a propriedade típica faça uso de dieta com concentrado e volumoso para engorda dos animais, nesta planilha são apresentadas as informações de produtos utilizados, o preço, a categoria do rebanho que o consome e suas respectivas quantidades. Também é analisada a forma da distribuição dos alimentos aos animais.

- Sanidade e medicamentos: são informados todos os processos e operações relacionados à vacinação, uso de medicamentos, identificação e insumos para reprodução. Assim como os dados de dieta, são apresentados os insumos utilizados, período e categoria do rebanho. $\mathrm{Na}$ produção de leite são considerados também os dados específicos da ordenha dos animais.

- Geral: os dados que não foram coletados nas planilhas anteriores estão contidos nesta, tais como custos administrativos, energia, impostos, seguros, juros de custeio e financiamentos, etc.

Vale destacar que os índices e custos declarados pelos participantes não estão relacionados com as suas respectivas propriedades, tampouco com a soma e média das propriedades dos participantes. 


\section{Propriedade típica}

Pela metodologia de painel, busca-se estabelecer os modelos produtivos que mais ocorrem regionalmente. É importante destacar que esse modelo, chamado de propriedade modal, típica ou representativa, é a moda da produção e não a média do que se encontra na região. Registra-se a estrutura que representa melhor o tamanho e o sistema produtivo das propriedades locais que ofertam a maior parte da produção - ainda que estas sejam em menor número. No início da década de 1960, Plaxico \& Tweeten ${ }^{[28]}$ já destacavam que o sistema de fazendas representativas é aplicável para estudos e políticas públicas para unidades produtivas do meio rural.

Em algumas áreas, a impossibilidade de determinar a tipicidade faz com que mais de uma propriedade, ou os sistemas de produção representados sejam estabelecidos - situação comum no levantamento de dados da pecuária de corte. É o caso de regiões para as quais acaba sendo necessário definir, por exemplo, uma propriedade típica de cria de gado e, na mesma região, uma propriedade típica de recria e engorda.

Ao final desse debate, pode-se dizer que toda a caracterização da propriedade típica da região tem o aval dos produtores rurais. Com isso, os índices de produtividade, custos de implantação, custos fixos e variáveis, ou seja, todos os números resultantes do painel tendem a ser bastante próximos da realidade da moda da produção regional.

Esta metodologia de definição das propriedades típicas é uma adaptação de sistemas de levantamento e acompanhamento de custos feitos em outros países, inclusive, através deste método a rede Agri Benchmark de economistas e especialistas agrícolas compara os custos de produção entre seus países membros para grãos, pecuária de corte, ovinocultura, entre outros; Além de participar desta rede, o Cepea/Esalq/USP usou esse tipo de metodologia para outros trabalhos de pesquisa de reconhecido rigor técnico como o Banco Mundial.

\section{Cálculo do custo de produção}

Os dados da definição das
propriedades típicas e preenchimento das
planilhas base dos painéis resultam nas
planilhas de análise administrativa. O cálculo
dos resultados é baseado na metodologia de
Matsunaga et al. ${ }^{[29]}$, do Instituto de Economia
Agrícola (IEA).

\section{Custo Operacional Efetivo (COE)}

O Custo Operacional Efetivo (COE) refere-se a todos os gastos assumidos pela propriedade ao longo de um ano. Divide-se este item em custos variáveis e custos fixos. Os custos variáveis, como o nome já define, são os custos que variam conforme a quantidade produzida, por exemplo: vacinas e medicamentos, suplementação mineral, concentrado, manutenção de benfeitorias, máquinas, forrageiras perenes e anuais. No caso da utilização de máquinas e implementos em operações como a manutenção de culturas perenes, anuais e pastagem, os valores da horamáquina e hora-implemento também são determinados. Além dos custos variáveis também são contabilizados os custos fixos, ou seja, aqueles gastos que não variam com a quantidade produzida, como, por exemplo, algumas benfeitorias, impostos, como o ITR e contribuição sindical.

\section{Custo operacional total (COT)}

O Custo Operacional Total (COT) refere-se à soma do COE com o valor das depreciações de benfeitorias, máquinas e implementos e animais de serviço. A depreciação das pastagens é contabilizada pelos gastos com insumos para reforma e remuneração da mão de obra para esta atividade. Neste item também há também a inclusão do pró-labore, referente à retirada mensal do produtor de acordo com sua participação no processo produtivo da propriedade.

\section{Cálculo das depreciações}

A depreciação das máquinas e dos implementos utilizados é igual aos cálculos das depreciações de construções, benfeitorias e equipamentos. Todos levam em consideração a depreciação linear, utilizando apenas o valor 
unitário, o valor residual e o tempo de vida útil em anos de cada bem, com a fórmula descrita abaixo.

Depreciação Linear $=\frac{\text { Valor de novo-Valor de sucata }}{\text { Vida útil }(\text { (anos) }}$

\section{Custo total (CT)}

Refere-se à soma do COT com a remuneração sobre o capital investido em benfeitorias, máquinas, implementos, equipamentos, utilitários, animais e forrageiras perenes, utilizando-se da taxa de $6 \%$, referente à aplicação financeira em poupança, sobre $\mathrm{O}$ montante aplicado nesses itens. Além da remuneração sobre o capital investido, há também o custo de oportunidade da terra, que acrescenta o valor do arrendamento mais utilizado na região (ex: sacas de soja, arroba de boi, etc.), na área utilizada pela pecuária leiteira e de corte.

Remuneração do Capital $=\left(\frac{\text { Valor de novo+Valor de sucata }}{2}\right) * 0,06$

\section{Cálculo da margem bruta (MB)}

A MB é obtida a partir da subtração do custo operacional efetivo (COE) da receita bruta calculada em cada painel. A partir desse dado é possível obter o retorno operacional efetivo anual por hectare, por arroba e litro de leite de cada região em estudo.

Margem Bruta $=$ Prod. média $*$ preço médio - COE

\section{Cálculo da margem líquida (ML)}

A ML é obtida a partir da subtração do custo operacional total (COT) da receita bruta calculada em cada painel. A partir desse dado é possível obter o retorno operacional total anual por hectare e por litro de leite de cada região em estudo.

Margem Líquida $=$ Prod. média $*$ preço médio - COT

\section{Acompanhamento mensal de preços}

Após a realização do painel, a evolução dos custos é acompanhada com periodicidade mensal. Por meio de pesquisas telefônicas em revendas de produtos agropecuários, são captadas as variações dos preços dos produtos em cada município onde fora realizado o painel. São obtidas também as explicações do mercado para tais mudanças de preços, que serão essenciais para o entendimento das variações regionais dos custos.

Para a pecuária de corte, são coletados preços de aproximadamente 4.000 insumos por mês. As variações dos preços nominais dos insumos alimentam a estrutura formada pelas informações originais obtidas no painel.

\section{RESULTADOS E DISCUSSÃO}

\section{Rentabilidade}

Antes de apresentar os resultados é importante fazer um destaque em relação à metodologia utilizada. Nos resultados dos painéis, a valorização da terra não é considerada. Qualquer previsão sobre este indicador poderia ser subestimada ou ainda superestimada, dadas as incertezas decorrentes da previsão dos valores imobiliários para propriedades rurais.

\section{Considerando o Custo Operacional} Efetivo (COE), dos 193 painéis de propriedades representativas, 181 apresentam a Receita Total superior ao COE. Em outras palavras, isso significa que $93,78 \%$ das propriedades apresentam Margem Bruta positiva. Desta forma, estas propriedades são viáveis economicamente no curto e médio prazo.

Em relação ao Custo Operacional Total (COT) que engloba o COE mais as depreciações, 112 propriedades típicas apresentam Receita Total superior ao COT, ou seja, 58,03\% apresenta Margem Líquida positiva. Estas são as propriedades que no longo prazo (tempo em que terão que renovar os equipamentos e reformar as pastagens) são capazes de pagar as suas dívidas. 
No entanto, $41,97 \%$ das propriedades, após o período de depreciação dos equipamentos, não conseguirá reinvestir na atividade, vendendo a área. Com o valor obtido pela terra, esses produtores certamente conseguem pagar as dívidas e ainda obtém uma reserva para investir em outra atividade. Este é justamente o processo de especulação descrito por Reydon [14], que ocorre com a compra, manutenção e posterior revenda da terra.

Considerando o Custo Total (CT), ou seja, aquele custo que considera o custo de oportunidade do capital investido, onde o custo de oportunidade da terra é determinado pelo valor do arrendamento, apenas 15 painéis apresentam Receita Total superior ao CT. Isso significa que na maioria absoluta dos painéis realizados, $92,23 \%$, as receitas geradas não são suficientes para pagar o custo de oportunidade do capital investido.

Considerando o período de análise, 2002 a 2014, não houve melhorias significativas entre os anos em relação à rentabilidade. Houve, em alguns parâmetros, melhoria nos indicadores de produtividade, como lotação por área, idade de abate, taxa de mortalidade, entre outros. Como agenda, sugere-se que sejam analisados horizontes temporais para uma mesma propriedade. Isso permitirá verificar se, em anos em que há elevações expressivas do valor da arroba ou do bezerro - como os recordes de preços registrados em 2010 e em 2014, o retorno econômico compensa o de anos anteriores.

Outro indicador de rentabilidade que deve ser observado é o comparativo as propriedades de agricultura. Apenas para exemplificar, no município de Naviraí/MS na safra 2013/2014, de acordo com os painéis do Cepea realizado pela equipe de grãos, $\mathrm{o}$ produtor de soja não é proprietário da terra, ou seja, é arrendatário e obteve como margem bruta $\mathrm{R} \$ 2.280,36 /$ hectare e como margem líquida $\mathrm{R} \$ 1.864,12 /$ hectare. No mesmo município, para o mesmo período, o pecuarista, proprietário da terra, teve margem bruta de $\mathrm{R} \$ 789,59 /$ hectare e $\mathrm{R} \$ 540,45 /$ hectare como margem líquida.

\section{Fatores culturais}

Nos painéis sempre existe uma reclamação que a atividade não é remuneradora. Esta reclamação acompanha a expectativa de rentabilidade em comparação com os agricultores, principalmente produtores de soja, como apresentado anteriormente.

Se a reclamação é frequente, qual a motivação para os pecuaristas continuarem na atividade? A motivação mencionada em praticamente $100 \%$ dos painéis refere-se ao baixo risco da atividade. Mesmo que em um ano o clima seja severo e, por exemplo, uma seca acabe com o pasto, dificilmente esse produtor irá perder toda a sua produção, assim como ocorre com o produtor de soja. Esse produtor tem a opção de entrar com suplementação mineral e algum tipo de ração, ou ainda, pode vender os animais antes que esses comecem a perder peso.

Aliado ao risco, mas diferentemente dele, tem a incerteza em relação ao futuro. Neste caso, o pecuarista sabe que mesmo que tudo seja diferente do que ele espera, ele ainda tem a terra como um capital atraente com relativa facilidade para transforma-se em moeda. Terra também é um ativo que não se torna obsoleto e, salvo em caso de superutilização, também não se deteriora completamente.

A expectativa em relação ao aumento da terra não é mencionada de forma direta. No entanto, ao fim do painel quando os resultados são apresentados aos participantes, nas propriedades em que a receita não cobre $\mathrm{o}$ COT e o CT, os produtores afirmam que é aquilo mesmo que acontece, quando o pasto está esgotado e não há recursos disponíveis para reformá-lo, o produtor vende a área.

Além disso, a liquidez da atividade é outro fator importante. Um produtor de soja, por exemplo, vende a sua produção duas vezes por ano (safra e safrinha). Ele pode optar por esperar preços melhores estocando a sua produção. No entanto, estocar implica em mais custos. 
Já o pecuarista pode vender o animal o ano todo, sem custos adicionais de estoque. Além de vender o boi gordo, aquele animal pronto para o abate, o pecuarista pode vender qualquer um dos seus animais. Por exemplo, em uma propriedade de ciclo completo, ele pode vender o boi magro para uma propriedade de finalização, vender o bezerro para engorda, ou ainda pode vender as vacas reprodutoras para abate.

Dessa forma, há uma liquidez de mercado muito maior do que a do produtor de soja que se dá em cada uma das fases da produção. Estas são variáveis que o modelo de custo de produção anual, como o aplicado neste artigo, não consegue captar. Para isso, seria crucial realizar uma análise com horizontes temporais plurianuais. Além disso, em um cenário de emergência, que precise de dinheiro rapidamente, o pecuarista não precisa esperar o tempo de colheita para receber seu dinheiro.

Por fim, outro fator frequentemente mencionado é o histórico familiar. O pai ou avô aventurou-se na atividade e este produtor continua. Este, inclusive, é um motivo pelo qual o pecuarista não inova. Ele prefere manter o modelo de produção como o dos seus antepassados.

\section{CONCLUSÕES}

Os dados apresentados demonstram que a melhor alternativa econômica para muitos pecuaristas seria vender os seus ativos e investir o dinheiro no mercado financeiro. Este resultado ocorre, pois a metodologia não estima a valorização da terra. Com efeito, não apenas a rentabilidade da venda dos animais é um fator importante na tomada de decisão por parte do produtor, mas a expectativa de valorização da terra também é um motivo relevante. Comparativamente a outras atividades agrícolas, o baixo risco e a elevada liquidez são determinantes na decisão de produzir dos pecuaristas.

A revisão de literatura indica que a escolha produtiva pela pecuária de corte, motivada também pelo uso especulativo da terra, não é coibida pelo modelo das instituições brasileiras formais que regulam a propriedade de terras por meio da sua função social. O cenário é de mudanças. Com a crise alimentar mundial e a alta dos preços dos alimentos é importante compreender esse processo para nortear as políticas públicas para um desenvolvimento rural socialmente mais justo e mais eficiente no uso dos recursos naturais, garantindo a segurança alimentar no campo e na cidade.

\section{REFERÊNCIAS}

[1] Sen A. The concept of development. In: Chenery $\mathrm{H}$, Srinivasan T, editors. Handbook of development economics. [local desconhecido]: Elsevier; 1988. p. $9-26$.

[2] Lavoie M. Introduction to post-Keynesian economics. Londres: PalgraveMacmillan, 2009. 184 p.

[3] Ronald HC. The nature of the firm. Econom. 1937;4(16):386-405.

[4] North DC. Five propositions about institutional change. In: Knight J, Sened I, editors. Explaining social institutions. Ann Arbor: Michigan Universiy Press; 1995. p. 15-26.

[5] Fligstein N. Markets as politics: a political-cultural approach to market institutions. Am. Sociol. Rev. 1996;61(4):656-73.

[6] Abramovay R. Para uma teoria dos estudos territoriais. In: Ortega AC, Almeida Filho N. Desenvolvimento territorial, segurança alimentar e economia solidária. Campinas: Alínea; 2007. p. 1937.

[7] Kageyama A. Desenvolvimento rural: conceito e medida. Cad Cien Tecnol. 2004;21(3):379-408.

[8] Brasil. Constituição (1988). Constituição da República Federativa do Brasil. Brasilia, DF, 5 out. 1998. Artigos 184 a 186.

[9] Furtado C. Formação econômica do Brasil. São Paulo: Companhia Editora Nacional; 1979. 242 p.

[10] Garfield S. As raízes de uma planta que hoje é o Brasil: os índios e o Estado-Nação na era Vargas. Rev Bras. Hist. 2000;20(39):15-42.

[11] Santiago AA. O Zebu na Índia, no Brasil e no mundo. Campinas: Instituto Campineiro de Ensino Agrícola; 1972. 744 p. 
[12] Ichihara SM. Desmatamento e recuperação de pastagens degradadas na região Amazônica: uma abordagem através das análises de projetos. [dissertação]. Piracicaba: Universidade de São Paulo; 2003.

[13] Brasil. Lei 8.629, de 25 de fevereiro de 1993. Dispõe sobre a regulamentação dos dispositivos constitucionais relativos à reforma agrária, previstos no Capítulo III, Título VII, da Constituição Federal. Diário Oficial da União, Brasília, DF, 26 fev. 1993. Item II do parágrafo $2^{\circ}$ do Art. $6^{\circ}$.

[13] Brasil. Lei 8.629, de 25 de fevereiro de 1993. Dispõe sobre a regulamentação dos dispositivos constitucionais relativos à reforma agrária, previstos no Capítulo III, Título VII, da Constituição Federal. Diário Oficial da União, Brasília, DF, 26 fev. 1993. Item II do parágrafo $2^{\circ}$ do Art. $6^{\circ}$.

[14] Reydon BPA. Regulação institucional da propriedade da terra no Brasil: uma necessidade urgente. In: Ramos P. Dimensões do agronegócio brasileiro: políticas, instituições e perspectivas. Brasilia: Ministério do Desenvolvimento Agrário (BR); 2007. (NEAD-Estudos 15).

[15] Instituto Brasileiro de Geografia e Estatística. Efetivo dos rebanhos, 2014 Disponivel em: http://www.sidra.ibge.gov.br/bda/tabela/listabl.asp $?_{\mathrm{z}}=\mathrm{t} \& \mathrm{o}=24 \& \mathrm{i}=\mathrm{P} \& \mathrm{c}=3939$

[16] Neiva AH. A imigração na política brasileira de povoamento. Rev Bras Munic. 1949;2(6):220-44.

[17] Rivero S, Almeida O, Ávila S, Oliveira, W. Pecuária e desmatamento: uma análise das principais causas diretas do desmatamento na Amazônia. Nov Econ. 2009;19(1):41-66.

[18] Instituto Nacional de Pesquisas Espaciais Inpe. Projeto Prodes - Programa de Cálculo do Desflorestamento da Amazônia, 2014. Disponível em: http://www.obt.inpe.br/prodes/index.php

[19] Margulis S. Causas do desmatamento da amazônia brasileira. Brasília: Banco Mundial, 2003. $100 \mathrm{p}$.
[20] Almeida MHSP. Análise econômico-ambiental da intensificação da pecuária de corte no CentroOeste brasileiro [dissertação]. Piracicaba: Universidade de São Paulo; 2010.

[21] Valentim JF, Andrade CMS. Tendências e perspectivas da pecuária bovina na Amazônia brasileira. Amazon Cien Desenvolv. 2099;4(8):9-32.

[22] Timmer CP. The macro dimensions of food security: economic growth, equitable distribution, and food price stability. Food Policy. 2000;25(3);28395.

[23] Van der Ploeg JD. Componeses e impérios alimentares: lutas por autonomia e sustentabilidade na era da globalização. Porto Alegre: UFRGS, 2008. Capítulo 9, Império, alimentos e agricultura: uma síntese; p. 255-84.

[24] North DC. Understanding institutions. In: Menard C, editor. Institutions contracts and organizations - perspectives from new institutional economics. Chelteenham: Edward Elgar; 2000. p. 07-10.

[25] Mcmichael P. A food regime genealogy. J Peasant Stud. 2009;36(1):139-69.

[26] Centro de Estudos Avançados em Economia Aplicada - dados primários - Projeto Custo de Produção em Pecuária de Corte, 2002-2014. Cepea. Piracicaba. Disponível em: http:/ / cepea.esalq.usp.br/boi/?page $=372$

[27] Thiollent M. Metodologia da pesquisa-ação. São Paulo: Cortez; 1986. 108 p.

[28] Plaxico JS, Tweenten LG. Representative farms for policy and projection research. J Farm Econ. 1963;45(5): 1458-65.

[29] Matsunaga M, Bemelmans PF, Toledo PEN, Dulley RD, Okawa H, Pedroso IA. Metodologia de custo de produção utilizado pelo IEA. Agric São Paulo.1976;23(1):123-39. 